\title{
NURSES' SETTLEMENT NEWS
}

From Miss Dock we learn that the Nurses' Settlement in New York is happy in several important additions to its work. A most gratifying and needed extension in the visiting nursing service has been made in an upper west side region where the colored people live. Salaries have been given for two nurses, who are also colored, and who have settled in their district in a flat. The work is fortunate indeed in the rare ability and devotion of these two women, Mrs. Tyler and Miss Carter, both of whom are graduates of the Freedman's Hospital in Washington. Besides being excellent nurses they are both especially alive to social movements and organized preventive work. There is living with them a Miss Brown, who is engaged in social work among young girls. The craving "back to the land" is being a conspicuous feature of the Settlement, for this summer has seen two more country places acquired; one a house up the Hudson Valley holding about ten people for the Italians of the Sullivan Street district, and the other a beautiful old-fashioned farm near Yorktown Heights, the possibilities of which are quite limitless, for it has almost 100 acres of farm, woodland, hill, and valley, with a lovely old house to which a considerable extension is being made. Then the camp for boys and young men near Peekskill has never been so successful as this year, and the "Rest" for convalescents, the Vacation House for young girls, and the farm at Montclair for children, are all running happily and prosperously. Miss Phillpotts, of St. Luke's, Chicago, is at the last named place for the summer. Miss Rogers has been up at Otisville at the new sanitarium for incipient tuberculosis under the Board of Health, getting it started and systematized, and Miss Frank is the visitor for the beautiful new Betty Loeb Convalescent Home, to see and investigate applicants for free admission.

A nurse from the District Nursing Association of Kalamazoo, Miss MacClure, is spending a month of observation and study at the Settlement, and a number of transients are there for the summer. The Settlement has recently acquired the house next to 265 , and this is being put into shape for many uses. Miss Wald's time is greatly occupied with committee meetings, notably that for Child Labor and the assigning of "scholarships" or small incomes to replace the earnings of children in cases where the new child labor law would work hardship, and for a long time this spring she was almost incessantly busy with the opposition to a threatened elevated structure on the crowded East Side.

Miss Dock is again at the Settlement working on the History of 
Nursing which she is writing in collaboration with Miss Nutting. The first volume will be ready for publication at an early date.

\section{VACANCIES IN THE ARMY NURSE CORPS}

$W_{E}$ understand that there are several vacancies in the army nurse corps. Nurses who can meet the requirements can be assured of an early appoint ment.

\section{DOCTORS TAKE ACTION}

WE wish that all medical societies might be moved to pass resnlutions such as the following, and that the members might be depended upon to practice the principles so endorsed. This resolution is taken from the Pennsyliania Medical Journal and was of June, 1906:

WhereAs, Inducements are being widely offered for training nurses in socalled "correspondence schools" and short term "dispensary schools" in both of which systems bedside instruction is lacking; therefore,

Resolved, That the Philadelphia County Medical Society hereby declares that any system of nurse training that disregards residence in a hospital and bedside instruction is dangerously incomplete, and

Resolved, That members of this society are requested to refrain from endorsing schools which lack bedside instruction, and

Resolved, That any member who has, previously to the adoption of these resolutions, endorsed such schools is requested to revoke such endorsement.

\section{THE SAN FRANCISCO DISASTER}

Is our July report on conditions in San Francisco, page 723, the total amount received at that time by the nurses' relief committee was given as $\$ 7,500$. This was a misprint, and should have read $\$ 1,500$. Since that date, we have received an itemized statement from the nurses' relief committee, giving the total receipts as $\$ 4,158.90$, and the disbursements to July 5 , as $\$ 1,175.70$. As these figures are now out of date, we will postpone the itemized list of donations until our next issue.

Miss Sweeney, who is in charge of the nurses' club house, 8 Steiner Street, reports the rooms as being nearly all furnished. The money which has been furnished for this purpose by the relief committee, of which Dr. Criswell is chairman, is considered as a loan and it is hoped, within a reasonable time, to put the club-house on a paying basis.

Since the San Francisco disaster we have heard much of the 